\title{
Technology for Recycling Magnesium Alloy Housings of Notebook Computers
}

\author{
Koichi Kimura $^{1}$, Kouta Nishii ${ }^{2}$ and Motonobu Kawarada ${ }^{2}$ \\ ${ }^{1}$ Electronics Packaging Laboratory, Materials \& Environmental Engineering Laboratories, \\ Fujitsu Laboratories Ltd., Akashi 674-8555, Japan \\ ${ }^{2}$ Materials \& Environmental Engineering Laboratories, Fujitsu Laboratories Ltd., Akashi 674-8555, Japan
}

\begin{abstract}
Magnesium housings, which are lightweight, strong, and have high heat radiation characteristics, are in widespread use for portable personal computers and similar devices. Another characteristic of magnesium alloy is that it is a metal that can be melted for recycling. There are two ways of recycling magnesium alloy housings, one for recycling excess material generated during the molding process and one for recycling collected magnesium alloy housings that have been painted. Whether the molding method is die casting or thixomolding, the housing weight accounts for only about $30 \%$ to $50 \%$ of the Mg alloy that is injected. The remaining $50 \%$ to $70 \%$ is sprue and runner, which are excess after molding. It is important to establish a method of recycling for the excess material by as cost reduction. However, the data available for the material that was recycled repeatedly was not adequate. This was an issue to resolve in promoting the recycling of $\mathrm{Mg}$ alloy housings. Notebook PCs collected from the market are encased in painted MG alloy housings. Now, painted Mg alloy housings is rarely recycled. In the former process, adjusting the composition of the magnesium alloy in the remelting process restores the same strength and corrosion resistance characteristics as the virgin material despite repeated recycling. In the latter process, soaking in a solution causes the paint to flake off the magnesium alloy housings. The remaining alloy that is then remelted and the adjusted composition can produce a recycled material having the same performance characteristics as the virgin material without generating much gas or dust in the remelting process. The technology for recycling excess material was first applied to the production of the Fujitsu PC FMV-BIBLO notebook that was marketed in 1999. The technology for recycling painted magnesium alloy housings will be applied in full starting in fiscal 2002.
\end{abstract}

(Received February 6, 2002; Accepted August 5, 2002)

Keywords: magnesium alloy, housing, recycling, thixomolding, remelting, wet blasting, solution treatment

\section{Introduction}

The revised Recycling Law was enacted to require the collection of personal computers (PC) discarded by corporations beginning in April 2001 and discarded by individuals beginning in April 2002. This law applies to four other kinds of household electronic devices as well. By weight, the housing of a PC accounts for about $30 \%$. This percentage makes the method of discarding and recycling a key in the recycling of PCs. Among portable PCs, the magnesium alloy and other similar metals are becoming popular for sturdy housings.

The specific gravity of $\mathrm{Mg}$ alloy is as low as about $70 \%$ of that of aluminum, a high specific strength, and high degree of heat radiation. $\mathrm{Mg}$ alloy housings are molded by die casting or thixomolding. Fujitsu uses thixomolding to manufacture most of its housings. In thixomolding, an injection molder injects semi-solid $\mathrm{Mg}$ alloy into a mold in a laminar flow using the thixotropy of the alloy. Compared with ordinary die casting, thixomolding is safe with a low possibility of combustion because the temperature of the molten alloy can be kept low and the supply of molten alloy can be fully automated. Whether the molding method is die casting or thixomolding, the housing weight accounts for only about $30 \%$ to $50 \%$ of the $\mathrm{Mg}$ alloy that is injected. The remaining $50 \%$ to $70 \%$ is sprue and runner, which are excess after molding. It is important to establish a method of recycling for the excess material by considering the global environmental as well as cost reduction. In an article on die-cast moldings, Sato et al. ${ }^{1)}$ reported that recycled of $\mathrm{Mg}$ alloy satisfied JIS standards. With thixomoldings, the recycled material was also reported ${ }^{2,3)}$ to satisfy JIS standards and was the same as the initial (virgin) material. However, the data available for the material that was recycled repeatedly was not adequate. This was an issue to resolve in promoting the recycling of Mg alloy housings. Notebook PCs collected from the market are encased in painted $\mathrm{Mg}$ alloy housings. Tatsuishi et al. reported the generation of a poisonous gas and a decrease in the material yield when die-cast moldings using a small amount of painted $\mathrm{Mg}$ alloy were recycled. ${ }^{4,5)}$ Matsunaga et al. reported on the recycling of thixomoldings after being sandblasted to strip off the paint. ${ }^{6)}$ This method, however, has disadvantages relative to productivity and safety. Notebook PCs with paint several dozen microns thick are no longer recycled. With the goal of recycling used notebook PC housings, the authors investigated recycling techniques for housings made of painted $\mathrm{Mg}$ alloy.

\section{Experimental Method}

\subsection{Methods of producing recycled materials}

Recycled materials are produced two ways from $\mathrm{Mg}$ alloy housings. One method is a remelting method where a refinery remelts the $\mathrm{Mg}$ alloy housings and excess material, produces ingots after the refinery process, and converts the ingots into chips. The other is a direct method where $\mathrm{Mg}$ alloy housings and excess material are directly converted into chips at the molding site without remelting. For higher productivity, the authors selected the remelting method after comparing that method with the direct method using the quality of recycled materials and the generation of noise during the crushing of nonstandard-shape moldings as criteria. 


\subsection{Characteristics of repeated recycling}

\subsubsection{Repetition process}

The characteristics of repeated recycling of materials produced by the remelting method were studied. The authors repeated the following procedure ten times:

- Creating chips from a virgin material of the AZ91D alloy composition listed in Table 1, -Molding the chips, -Sampling three arbitrary moldings, -Remelting the remaining moldings, runners, and sprues, producing ingots, and creating chips.

\subsubsection{Recycled materials}

The following recycled materials were experimentally produced by remelting:

(1) $100 \%$ recycled material

(2) Recycled material having a composition adjusted by adding aluminum and manganese.

\subsubsection{Characteristics of recycled materials}

The $\mathrm{Mg}$ alloy composition of each recycled material was checked. Each sample was measured by an ICP emission spectroscopic analyzer (SPS1700HVR, Seiko Instruments, Inc.) for nine different elements ( $\mathrm{Al}, \mathrm{Zn}, \mathrm{Mn}, \mathrm{Si}, \mathrm{Fe}, \mathrm{Cu}$, and $\mathrm{Ni}$ ) and other substances making up $10 \mathrm{ppm}$ or more. For the measurement, about $0.5 \mathrm{~g}$ of each sample was dissolved in $10 \mathrm{~mL}$ of hydrochloric acid with ultrapure water added to adjust the total volume to $100 \mathrm{~mL}$.

The moldings were created from the recycled materials and measured for bending characteristics and for corrosion resistance. Using the repetition process, the authors created and evaluated liquid crystal display (LCD) covers for the FMV-BIBLO MS (fujitsu 's notebook computer), as shown in Fig. 1. For molding, a thixomolding machine (JLM650-MG, Japan Steel Works, Ltd.) was used at a cylinder temperature of $615^{\circ} \mathrm{C}$ and a mold temperature of $250^{\circ} \mathrm{C}$. Test specimens $(50 \mathrm{~mm} \times 100 \mathrm{~mm})$ were cut from the sample moldings and were subjected to a three-point bending test. The test conditions conformed to JIS K 7055. For the test, a universal material tester (INSTRON 5581, Instron Corporation) was used at

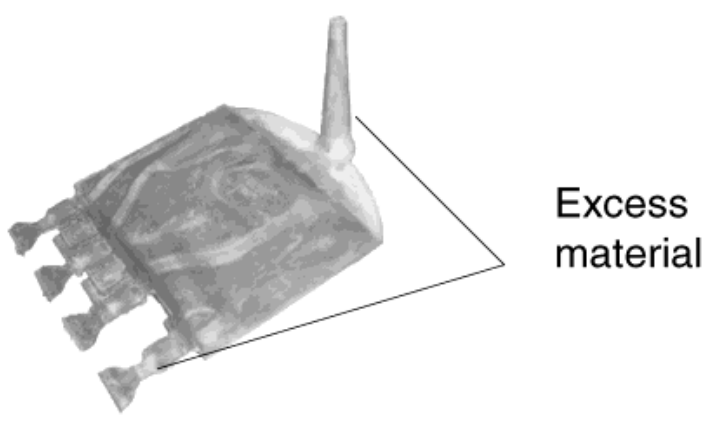

Fig. 1 Mg alloy housing.

a load speed of $2 \mathrm{~mm} / \mathrm{min}$ and a span length of $30 \mathrm{~mm}$. In addition, test specimens $(64 \mathrm{~mm} \times 12.7 \mathrm{~mm})$ were cut from the sample moldings and subjected to an Izod impact test. The test conditions conformed to JIS K 7110. An Izod impact tester (B-121202403, TOYO SEIKI Co., Ltd.) was used for the test.

Corrosion resistance was evaluated by a saltwater atomization test. The test method conformed to JIS Z 2371. The resistance was evaluated by measuring the weight change after saltwater atomization. The test conditions are as follows:

—Test liquid: $5 \% \mathrm{NaCl}$, -Temperature: $35 \pm 2{ }^{\circ} \mathrm{C}$, -Salt spray time: $100 \mathrm{~h}$.

\subsection{Paint stripping process}

Paint is either stripped mechanically or chemically from painted notebook PCs. Sandblasting, a mechanical method is the most popular. However, sandblasting has a disadvantage that there is a danger of an explosion caused by $\mathrm{Mg}$ dust. Therefore, the authors jetted an abrasive in water for wet blasting to strip off the paint. A chemical method is to treat the housing with a solution to strip off the paint. However, since the type and manufacturer of the paint vary greatly

Table 1 Composition of recycled material.

\begin{tabular}{|c|c|c|c|c|c|c|c|c|c|}
\hline \multicolumn{2}{|c|}{ Element } & $\mathrm{Al}$ & $\mathrm{Zn}$ & $\mathrm{Si}$ & $\mathrm{Mn}$ & $\mathrm{Cu}$ & $\mathrm{Fe}$ & $\mathrm{Ni}$ & $\mathrm{Mg}$ \\
\hline \multicolumn{2}{|c|}{ AZ91D (ASTM standard) } & $8.5-9.5$ & $0.45-0.9$ & $\leqq 0.05$ & $0.17-0.4$ & $\leqq 0.025$ & $\leqq 0.004$ & $\leqq 0.001$ & Remainder \\
\hline \multicolumn{10}{|c|}{ Number of times recycled } \\
\hline \multirow[b]{2}{*}{2} & (1) $100 \%$ recycled material & 8.91 & 0.76 & 0.024 & 0.19 & 0.004 & 0.0015 & 0.0005 & Remainder \\
\hline & $\begin{array}{l}\text { (2) Recycled material } \\
\text { by adding } \mathrm{Al} \text { and } \mathrm{Mn}\end{array}$ & 8.95 & 0.75 & 0.022 & 0.21 & 0.003 & 0.0015 & 0.0005 & Remainder \\
\hline \multirow[b]{2}{*}{4} & (1) $100 \%$ recycled material & 9.07 & 0.76 & 0.019 & 0.18 & 0.003 & 0.0025 & 0.0001 & Remainder \\
\hline & $\begin{array}{l}\text { (2) Recycled material } \\
\text { by adding } \mathrm{Al} \text { and } \mathrm{Mn}\end{array}$ & 9.05 & 0.7 & 0.02 & 0.2 & 0.001 & 0.0011 & 0.0001 & Remainder \\
\hline \multirow[b]{2}{*}{6} & (1) $100 \%$ recycled material & 8.89 & 0.77 & 0.012 & 0.14 & 0.003 & 0.0023 & 0.0001 & Remainder \\
\hline & $\begin{array}{l}\text { (2) Recycled material } \\
\text { by adding } \mathrm{Al} \text { and } \mathrm{Mn}\end{array}$ & 9.05 & 0.78 & 0.01 & 0.19 & 0.001 & 0.0013 & 0.0009 & Remainder \\
\hline \multirow[b]{2}{*}{8} & (1) $100 \%$ recycled material & 8.99 & 0.69 & 0.018 & 0.13 & 0.003 & 0.003 & 0.0006 & Remainder \\
\hline & $\begin{array}{l}\text { (2) Recycled material } \\
\text { by adding } \mathrm{Al} \text { and } \mathrm{Mn}\end{array}$ & 9.25 & 0.71 & 0.016 & 0.2 & 0.003 & 0.001 & 0.0003 & Remainder \\
\hline \multirow[b]{2}{*}{10} & (1) $100 \%$ recycled material & 9.3 & 0.778 & 0.052 & 0.11 & 0.004 & 0.0028 & 0 & Remainder \\
\hline & $\begin{array}{l}\text { (2) Recycled material } \\
\text { by adding } \mathrm{Al} \text { and } \mathrm{Mn}\end{array}$ & 9.2 & 0.629 & 0.027 & 0.19 & 0.0014 & 0.0014 & 0.001 & Remainder \\
\hline
\end{tabular}


between housings, the stripping characteristics are not constant. Therefore, we evaluated several stripping agents and conditions.

\subsubsection{Wet blasting}

Wet blasting consists of a water jet containing an abrasive at high speed from a jet nozzle driven by compressed air. To

Table 2 Results of solution stripping.

\begin{tabular}{|c|c|c|c|}
\hline & \multicolumn{3}{|c|}{ Stripping agents } \\
\hline & Stripping agents $\mathrm{A}$ & Stripping agents B & Stripping agents C \\
\hline \multicolumn{4}{|l|}{ (1)Paint manufacturer $\mathrm{T}$} \\
\hline \multicolumn{4}{|l|}{ Paint A } \\
\hline \multicolumn{4}{|l|}{ (2) Paint manufacturer $\mathrm{A}$} \\
\hline \multicolumn{4}{|l|}{ Paint A } \\
\hline \multicolumn{4}{|l|}{ (3) Paint manumacturer S } \\
\hline \multicolumn{4}{|l|}{ Paint B } \\
\hline \multicolumn{4}{|l|}{ (4) Paint manufacturer $\mathrm{T}$} \\
\hline \multicolumn{4}{|l|}{ (5)Paint manufacturer $\mathrm{A}$} \\
\hline \multicolumn{4}{|l|}{ Paint A } \\
\hline \multicolumn{4}{|l|}{ (6) Paint manufacturer $\mathrm{C}$} \\
\hline \multicolumn{4}{|l|}{ Paint C } \\
\hline & D & & a \\
\hline & & & \\
\hline
\end{tabular}

Stripping agents $A$

: Sodium hydroxide

Monoethanolamine

Ethylene glycol monoethyl ether

Stripping agents $B$

: Sodium hydroxide

Surfactant

Benzyl Alcohol

Stripping agents $\mathrm{C}$

:Potassium hydroxide.

Sodium hydroxide

Surfactant

Alcohol 
evaluate the stripping performance of wet blasting, the authors checked the amount of paint residue on the housing, as shown in Fig. 1, and comparing it with variations in the jet nozzle speed. Alumina \#200 was used as the abrasive.

\subsubsection{Solution treatment}

Nine kinds of PC Mg alloy housings painted with paints of different manufacturers were dipped into stripping agents for the paint-stripping test Stripping agents A to C consisted primarily of alkali elements. In the test, each painted $\mathrm{Mg}$ alloy housing was dipped into a stripping agent heated to $70^{\circ} \mathrm{C}$. After $1.5 \mathrm{~h}$ soaking, the housing was washed with water and the degree of stripping evaluated. The compositions of agents A to $\mathrm{C}$ were shown in Table 2 .

\subsection{Recycling of painted Mg alloy housings 2.4.1 Samples}

From the painted $\mathrm{Mg}$ alloy housings stripped by the wet blasting and solution treatment in the previous section, the following materials were created by remelting, as explained in Section 2.1: materials recycled from (1) an unpainted $\mathrm{Mg}$ alloy housing, (2) a painted $\mathrm{Mg}$ alloy housing, (3) a Mg alloy housing when the paint stripped area was changed to $50 \%$, $80 \%$, and $90 \%$ by varying the jet nozzle speed in wet blasting and (4) a Mg alloy housing after the paint was stripped off by solution treatment using stripping agent $\mathrm{C}$.

\subsubsection{Amount of gas}

The amount of gas generated during the remelting of the $\mathrm{Mg}$ alloy housings in the previous section was measured. For this measurement, a gas collection pipe was attached to the suction cover of the melting furnace and an Stainless steelmade pipe was extended outside the melting furnace. A Tenax tube was connected to the pipe to collect the gas by the use of a pump. With the Tenax tube used for gas collection, TCTGC-MS analysis was done. Before measurement, the Tenax tube was purged for three minutes to eliminate moisture.

\subsubsection{Amount of dust}

The amount of dust generated during remelting was also measured. For this measurement, a filter with glass fiber filter paper (for collecting any suspended particulates) was attached to the pipe to collect the dust while the gas was being collected. The dust-collection filter paper was dried and weighed to determine the amount of dust.

\subsubsection{Metal yield}

After the Mg alloy housings were remelted, the amount of metal yielded from the recycled material was obtained by measuring the amount of sludge remaining in the melting furnace.

\subsubsection{Characteristics of recycled materials}

The characteristics of recycled materials was evaluated in the same way as in Section 2.2.3.

\section{Experimental Results and Discussion}

\subsection{Repeated recycling characteristics}

\subsubsection{Composition analysis}

The Comparison of the $\mathrm{Mg}$ alloy that was recycled repeatedly was analyzed for any changes (Table 1). Figure 2 shows the changes in the amount of Fe; Fig. 3 shows the changes in the amount of Mn. Figure 2 shows that repeated recycling increases the percentage of $\mathrm{Fe}$ in the material. The reason



Number of Times Recycled

Fig. 2 Change in amount of Fe.



Fig. 3 Change in amount of Mn.

for this is that Fe is mixed in when the ingots are chipped. Figure 3 shows that repeated recycling decreases the percentage of Mn. This is because Mn takes in the increased Fe as an inter-metallic compound between $\mathrm{Al}$ and $\mathrm{Mn}$ and settles it out during refining to clean the molten alloy. The amount of Mn probably decreased because Mn was combined with the Fe mixed in during chipping or in the thixomolding process during recycling, and precipitated as sludge. In Figs. 2 and 3 , the addition of $\mathrm{Al}$ and $\mathrm{Mn}$ to adjust the composition during remelting suppresses the decrease of $\mathrm{Mn}$ and controls the amount of Fe despite repeated recycling.

\subsubsection{Strength}

Figure 4 shows the results of the bending test and Izod impact test. In this figure, Young's modulus in the repeatedly recycled material shows almost the same strength with a slight variation of about $10 \%$, regardless of the number of times the material is recycled. The Izod impact strength shows the same tendency as the bending strength. These results indicate that the remelting method retains the bending and Izod impact strengths and that they are not influenced by repeated 


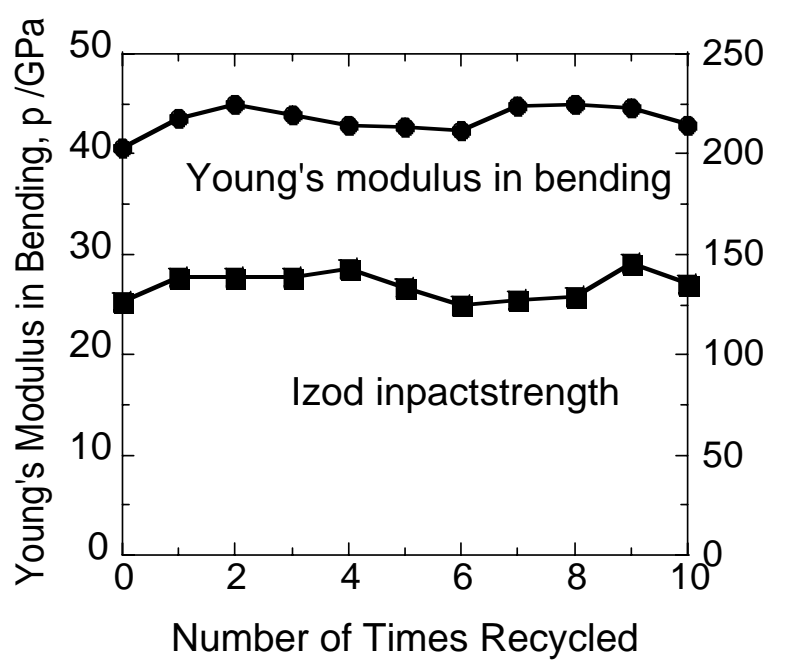

Fig. 4 Strength characteristics.

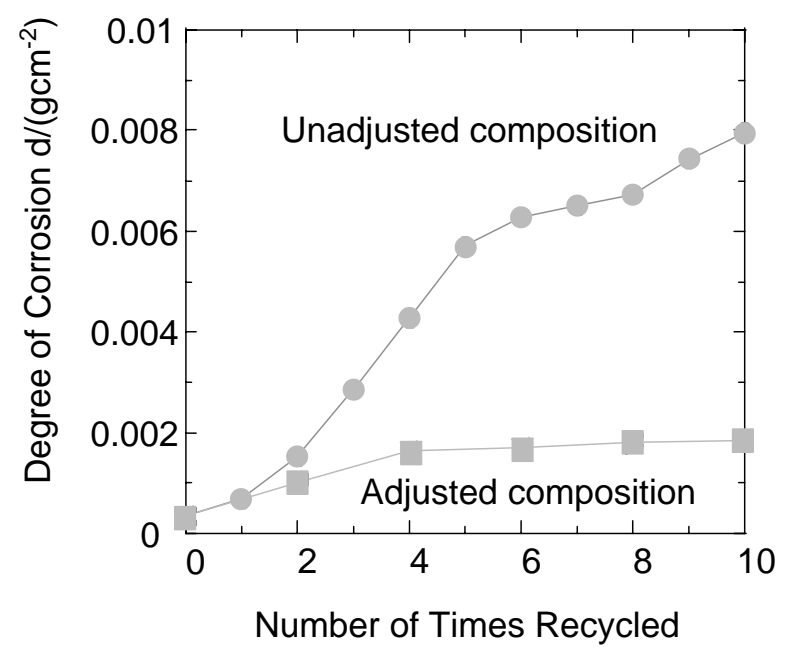

Fig. 5 Corrosion resistance.

recycling.

\subsubsection{Corrosion resistance}

Figure 5 shows the results of the corrosion resistance test. In this figure, the corrosion of a recycled material progresses as recycling is repeated. The corrosion of a molding created from a material recycled 10 times was more than 30 times greater than that of a molding created from virgin material. The primary impurities responsible for $\mathrm{Mg}$ alloy corrosion are $\mathrm{Fe}, \mathrm{Cu}$, and $\mathrm{Ni}$. Since these metallic elements and their intermetallic compounds form cathode parts of low hydrogen overvoltages, the $\mathrm{Mg}$ is greatly corroded. The aforementioned results of composition analysis indicate that repeated recycling increases the amount of $\mathrm{Fe}$ and decreases the amount of $\mathrm{Mn}$, and corrosion progresses accordingly. During remelting process, the addition of $\mathrm{Al}$ and $\mathrm{Mn}$ could suppress any decrease in $\mathrm{Mn}$ and control the amount of Fe, despite repeated recycling. A molding made of an adjusted composition showed almost the same degree of corrosion as one created from virgin material. The results indicate that corrosion resistance that is not inferior to that of the virgin material can be achieved even after repeated recycling if the percentages of $\mathrm{Mn}$ and $\mathrm{Fe}$ are kept constant by composition adjustment

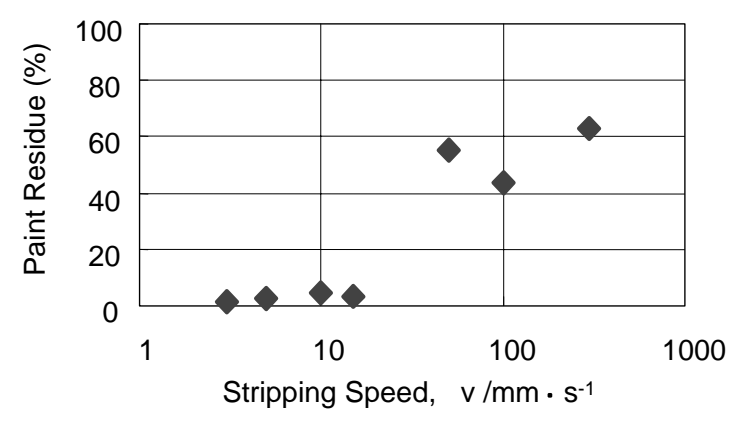

Fig. 6 Stripping performance of wet-blast processing.

during remelting.

\subsection{Paint stripping performance \\ 3.2.1 Wet blasting}

Figure 6 shows the results of comparing the jet nozzle speed and the paint residue on painted notebook PCs. In this figure, the percentage of paint remaining on the housing surface is more than $50 \%$ at a speed of $50 \mathrm{~mm} / \mathrm{s}$ or more and only a few percent at $10 \mathrm{~mm} / \mathrm{s}$ or less. In wet blasting, if the jet nozzle speed is set too low, not only the paint on the housing surface but also the $\mathrm{Mg}$ alloy itself may flake off. Therefore, the optimum jet nozzle speed was found to be from 5 to $10 \mathrm{~mm} / \mathrm{s}$

\subsubsection{Solution treatment}

Table 2 lists the results of the stripping test. When stripping agents $\mathrm{A}$ and $\mathrm{B}$ were used, the paint did not flake off. When stripping agent $\mathrm{C}$ was used, all paint came off. The stripping agent $\mathrm{C}$ permeated into the paint by osmosis, expanded, and caused the paint to flake off the housing surface.

\subsection{Recycling of painted Mg alloy housings 3.3.1 Amount of gas}

Table 3 lists the results of measuring the amount of gas generated from $\mathrm{Mg}$ alloy housings during the remelting by wet blasting and soaking in solution. The table shows that the least amount of gas (benzene) is generated when the $\mathrm{Mg}$ alloy housing is remelted after the paint is stripped off by soaking in solution. The next least amount of gas is generated when the $\mathrm{Mg}$ alloy housing is remelted after the paint is stripped off by wet blasting. The amount of gas generated is less than one-half that generated from an unpainted housing. The processing of unpainted housings generated more gas than housings stripped by wet blasting or solution treatment because the mold release agent sticking to the surface burns off. Figure 7 summarizes the amounts of gas generated when the stripped area varied. In this figure, the total amount of generated gas is about $5 \%$ or less of the amount of gas generated from a painted Mg alloy housing when the stripped area is $90 \%$ or more. The types of gas that are generated include benzene, toluene, and acrolein. Since these types of gas are stimulants, stripping off the paint is essential and the amount of gas generated is greatly affected by percentage of the stripped area.

\subsubsection{Amount of dust}

Table 3 lists the results of measuring the amount of dust generated from the processing of one $\mathrm{Mg}$ alloy housing during remelting. In this table, the amount of dust that is generated becomes smaller as the area of paint stripping increases. 
Table 3 Comparison of characteristics.

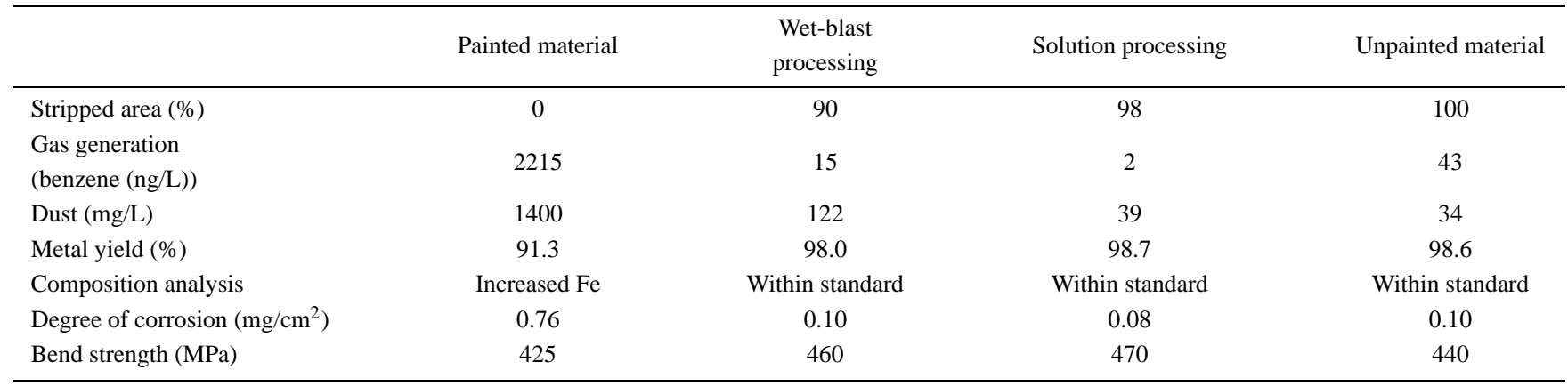

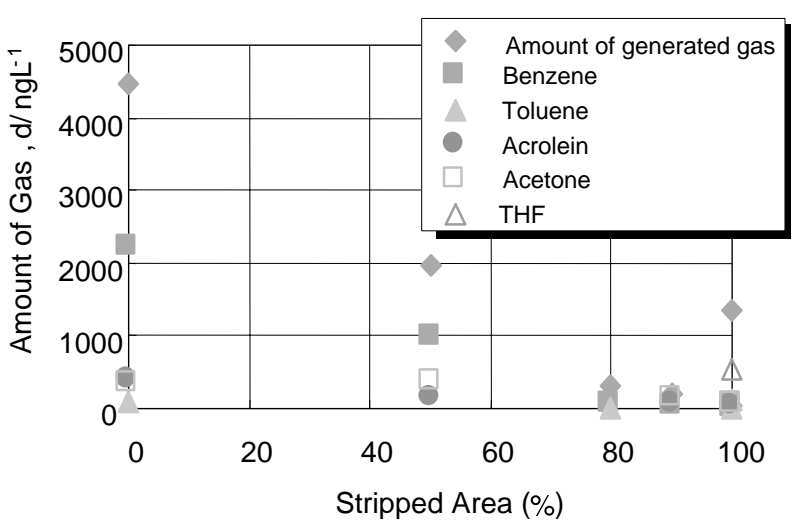

Fig. 7 Amount of generated gas.

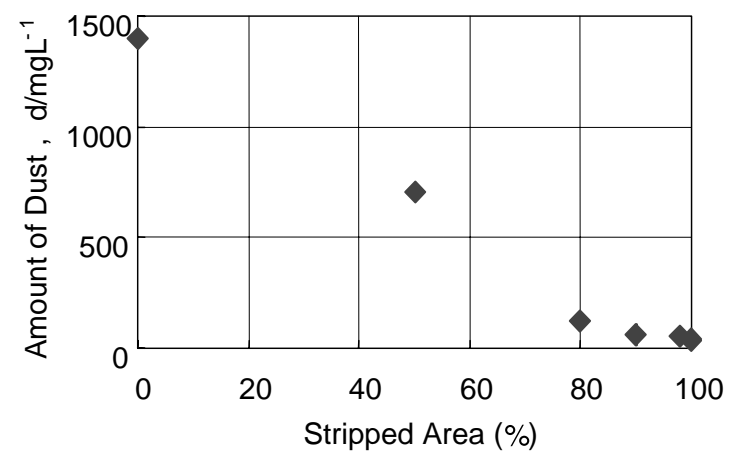

Fig. 8 Amount of generated dust.

Housings stripped of $98 \%$ of their paint by the solution treatment generate almost the same amount of gas as an unpainted housing. Figure 8 gives the results of measuring the amount of gas generated as the stripped area was varied. In this figure, the dust from a housing stripped of $90 \%$ or more of its paint is about $5 \%$ or less of that from a painted $\mathrm{Mg}$ alloy housing. The temperature of the furnace for remelting the $\mathrm{Mg}$ alloy is about $680^{\circ} \mathrm{C}$. Since this temperature is not high enough to burn the paint and tends to cause incomplete combustion, the percentage of stripped area greatly affects the amount of gas that is generated.

\subsubsection{Metal yield}

Table 3 lists the results of evaluating the amount of metal yielded by remelting the $\mathrm{Mg}$ alloy. Stripping off the paint increases the yield so much so that the yield is almost equal between solution-treated housings and untreated ones. Wetblasted housings also show a high yield with a difference of not more than $1 \%$. When painted $\mathrm{Mg}$ alloy housings are used, $\mathrm{Ti}$, alumina, and other impurities in the paint increase the amount of sludge. This is why the metal yield is low.

\subsubsection{Composition analysis}

Table 3 lists the results of the composition analysis. In the table, both wet-blasted and solution-treated housings have values within the AZ91D standard range. They produce molten alloy of the same composition as that of unpainted housings. When painted Mg alloy housings are used, Ti, alumina, and other impurities in the paint contaminate the molten metal.

\subsubsection{Comparison of properties}

Notebook PC housings were molded from recycled materials. Table 3 lists the results of evaluating their bending characteristics and corrosion resistance. In the table, both wetblasted and solution-treated $\mathrm{Mg}$ alloy housings show values equal to those of unpainted and painted housings. The dispersion is within $10 \%$, and paint or the lack of paint does not affect the bending characteristics. As Table 3 shows, the amount of corrosion of a housing molded from recycled material (created from a painted $\mathrm{Mg}$ alloy housing stripped by wet blasting and solution treatment) is about $13 \%$ of that of a painted $\mathrm{Mg}$ alloy housing.

\subsubsection{Summary}

Paint should be stripped off painted $\mathrm{Mg}$ alloy housings before they are recycled. Paint is stripped off by wet blasting or solution treatment as mentioned before. Both methods produce a recycled material with characteristics equal to those of materials created from unpainted housing. However, wet blasting is not very applicable to the standing walls of housing or debris. Solution treatment is effective for stripping paint off painted Mg alloy housings because the process is not affected by the shape of the housing.

\section{Conclusion}

For recycling notebook PCs housings made of the Mg alloy, the authors studied a variety of techniques for recycling excess material generated during molding and for recycling painted $\mathrm{Mg}$ alloy housings.

(1) Recycled material whose composition is adjusted by adding $\mathrm{Al}$ and $\mathrm{Mn}$ during remelting has strength and corrosion resistance equal to virgin material.

(2) Stripping is essential for painted $\mathrm{Mg}$ alloy housings. 
The percentage of stripped area greatly affects the amounts of gas and dust generated during remelting.

(3) $\mathrm{Mg}$ alloy housings whose paint is stripped off have performance equal to virgin material.

(4) Treatment with a solution was found more effective for stripping off paint than wet blasting.

The technology for recycling excess material was first applied to the manufacture of mobile notebook PCs marketed in 1999. Full-scale recycling of painted $\mathrm{Mg}$ alloy housings will begin in fiscal 2002.

\section{REFERENCES}

1) The Japan Magnesium Association: A Report on the Establishment of a Method for Refining a Magnesium Alloy Recycled Material and Judging the Level of Refinement, (1998).

2) K. Saito: Journal of the Japan Society of Polymer Processing 10 (1998) 16-23.

3) A. Maehara, T. Tsukeda and K. Saito: Polymer Processing 99 (1999) 179-180.

4) H. Tatsuishi, M. Inoue, S. Kamado, Y. Kojima, T. Itoh and M. Sugaya: J. Japan Inst. Light Metals 48 (1998) 19-24.

5) M. Inoue, M. Iwai, S. Kamado, Y. Kojima, T. Itoho and M. Sugama: Shigen-to-Sozai 115 (1999) 189-194.

6) K. Matsunaga, K. Matsumura, Y. Nishikawa, T. Soyama, H. Yasumoto, Y. Onishi, A. Isomi and Y. Kondo: Matsushita Technical Journal 47 (2001) $222-226$. 